\title{
Polysèmes
}

Revue d'études intertextuelles et intermédiales

\section{A Modernist Vernacular: Violent Figurations in Nathanael West's Miss Lonelyhearts}

William Dow

\section{(2) OpenEdition}

1 Journals

\section{Electronic version}

URL: http://journals.openedition.org/polysemes/1676

DOI: 10.4000/polysemes. 1676

ISSN: 2496-4212

\section{Publisher}

SAIT

Printed version

Date of publication: 1 January 2005

Number of pages: 185-201

ISSN: 0999-4203

\section{Electronic reference}

William Dow, «A Modernist Vernacular: Violent Figurations in Nathanael West's Miss Lonelyhearts »,

Polysèmes [Online], 7| 2005, Online since 01 January 2005, connection on 20 April 2019. URL : http:// journals.openedition.org/polysemes/1676 ; DOI : 10.4000/polysemes.1676

This text was automatically generated on 20 April 2019.

Polysèmes 


\title{
A Modernist Vernacular: Violent Figurations in Nathanael West's Miss Lonelyhearts
}

\author{
William Dow
}

1 Although the violence portrayed in American fiction often forms the base of dramatic action, or the conduit to tension and conflict, or the subversion of one's beliefs and attitudes, most critics are rightly dissatisfied with seeing violence as only a functional device in fiction. The ways in which writers create violence, as Michael Kowaleski notes, "determines the aesthetic force and perceptual impact that violence has" (4). By and large violence is described or witnessed, and thus it consists of the depictive energies of style: the sound and shapes of sentences, the movements and rhythms of syntax and imagery (Kowaleski 4). I am primarily concerned here not with the critical uses of violence as a theme but with the ways in which it has been imagined or "performed" in American fiction-the ways in which it exists not as an isolated element or subject but as the confirmation, at a given moment, of a larger stylistic field of force. Equally, I am concerned about how the reader appraises his or her moment by moment participation in verbal violence; and how this participation might be measured by powers of rendition rather than by efforts of understanding.

2 American literary criticism has certainly gone in the direction of overemphasizing the specialness of violence in human experience as some kind of ultimate stand off, some urgent sign of real life, focusing on the reasons for violence, on the sociocultural ideologies it purportedly exemplifies or encodes and the kinds of empathy or callousness our imaginative complicity in it promotes. ${ }^{1}$ I want to focus on several depictions of violence that do not merely serve a functional purpose and I want to analyze how violence has been conceived in and as a verbal form, the way it exists on the surface of works, not just thematically inscribed in them. I begin with the assumption that style reflects less a view of the world than the mind's form of address in considering it. Fictional violence in Nathanael West's Miss Lonelyhearts (1930), demands a technology of sensation, of experience, which, as Flannery O'Connor claims, "operates through the 
senses [...]. No reader who doesn't actually experience, who isn't made to feel, the story is going to believe anything the fiction writer merely tells him" (Bolton 90). For West, to articulate the violence is to falsify it, which is why he constantly presents it as a metaphoric or iconic meditation, self-consciously conceived. Language is its maker.

And yet I also want to bring in how and why texts make obvious appeals to the reader's emotions and use technical devices that both codify and in certain ways attempt to mold the values of their times. The effectiveness of, for example, Miss Lonelyhearts, derives essentially from its power to disturb. And finally I want to reassess the juncture of the performative and modernism by looking at how the nature of depicted violence forms a modernistic "vernacular": a term that combines the dimensions of the quotidian and mass culture forms with connotations of discourse, idiom, and dialect, and with the modernist preoccupations with style and effect. ${ }^{2}$

\section{Miss Lonelyhearts: Notes on Violence}

West's identification of violence with the essence of mainstream American society and culture is largely derived from his conviction that art could be transformed and rendered truly modern by life. Violence in Miss Lonelyhearts is thus suggested by innumerable actions and images, juxtapositions and paradoxes taken from mass culture-cinema, advertising, newspaper-and everyday occurrences. "Violent images are used to illustrate commonplace events," West writes in "Some Notes on Miss L" (1933). "Violent images are left almost bald"(2). "American violence," according to West, "is daily" and "idiomatic" ("Violence" 2), and therefore emotional descriptions of it, which in Europe would make sense as a position and response, are in the United States ineffectual and have lost all power of persuasion ("Violence" 2). As a result, for West, the task of the American artist is "to omit artistic excuses for familiar events" ("Violence" 2). As part of his vernacular of violence, West tries to grasp the world with the help of such negations: he tells the reader what that world is not, what it does not contain, what it does not know, what it is not aware of.

5 Thus routine descriptions in Miss Lonelyhearts are constantly scripted in violence, as in these images from the "Deadpan" chapter:

He entered the park at the North Gate and swallowed mouthfuls of the heavy shade that curtained its arch. He walked into the shadow of a lamp-post that lay on the path like a spear. It pierced him like a spear. (4)

6 When Miss Lonelyhearts finds himself "developing an almost insane sensitiveness to order," banal, inanimate objects entrap him ("his back to the wall"), and he violently tries to fight back:

When he touched something, it spilled or rolled to the floor. The collar buttons disappeared under the bed, the point of the pencil broke, the handle of the razor fell off, the window shade refused to stay down. He fought back, but with too much violence and was decisively defeated by the spring of the alarm clock. (11)

7 The banal events in West's work foreground a daily vernacular of violence in which the framework of human law is mere illusion and divine law is equally ineffectual. Both laws are negated, and their alternatives, West implies, can only be found in textuality. Although violent action in Miss Lonelyhearts is a subject required by a historical situationthe United States in the 1930s-and West engages a depression-era cultural discourse in which "Americanness" is increasingly understood as a matter of adaptation, violence is 
called for by the text and directly and extensively constructed in the text. Not surprisingly, for West, "Violent texts are left almost bald". Interpretation and commentary on violent scenes are non-existent in Miss Lonelyhearts. Instead of explication, or justification, or repulsion, West calls for a new subjectivity that issues from the text as a response to the old subjectivity displayed in the text. Furthermore, West's violence shares in typically modern contingency, in the class and economic uncertainties of the 1930s, and in its general foundationlessness of being. For West, the task of a narrative structure begins with the explosion of the conventional claim to transparency, teleological linearity, and subjective agency, that is, with the creation of violence and the concomitant destruction of the notion of cultural progress.

\section{Violent Structures}

West's modernist vernacular informs the structure of Miss Lonelyhearts. Like the brief, immediate strike of the violent act, the short lyrical novel, pared, based on brief portraits and quick imagistic renderings, is, for West, "a distinct form especially fitted for use in [the United States]" (Miss L., 2). Thus, West argues, "[1]yric novels can be written according to Poe's definition of a lyric poem" (Miss L., 2). Like Poe's views on the lyric poem (notably in "The Poetic Principle," 1850), West's on the short novel suggest that the novel is to be judged foremost by aesthetic criteria. Its task is to induce a particular kind of emotional response. "Forget the epic," West urges, "the master work" (Miss L., 2), a pronouncement that parallels Poe's dictum that "the ultimate, aggregate, or absolute effect of even the best epic under the sun, is a nullity" ("Principle", 338).

Indeed, West, in his abruptness, comic book-like techniques, disjunctions and discontinuities does violence to his own text. Shrike's press clipping in the "Deadpan" chapter serves to critically exfoliate the narrative facts (i.e., quickly established in the forms of letters from "Sick-of-it-all," "Desperate," and "Harold S.") with which West begins:

“ADDING MACHINE USED IN RITUAL OF WESTERN SECT..."

Figures Will Be Used for Prayers for Condemned Slayer of Aged Recluse...

DENVER, COLO., Feb. 2 (A.P.) Frank H. Rice, Supreme Pontiff of the Liberal Church of

America has announced he will carry out his plan for a "goat and adding machine"

ritual for William Moya, condemned slayer, despite objection to his program by a

Cardinal of the sect. (7)

But the sequence of ideas that follow this description are not unified by a structure of logical or narrative connectives. Like the narrative itself, the ideas generated by the narrative are offered as facts, as events for the reader to perceive. No explanation, no explicit justification or illumination of the underlying symbolism of Miss Lonelyhearts, or of the associational logic of the exposition (usually Shrike's), is given.

And yet West never strays too far from the realistic elements of his novel. Many episodes end in a literal violence. Examples abound: "Miss Lonelyhearts and the Lamb": "He crushed its head with a stone and left the carcass to the flies that swarmed around the bloody altar flowers" (10); "Miss Lonelyhearts and the Clean Old Man": "The old man began to scream. Somebody hit Miss Lonelyhearts from behind with a chair" (18); and "Miss Lonelyhearts Pays a Visit": "He kept hitting her until she stopped trying to hold him, then he ran out of the house" (50). Similarly, almost every joke erupts in violence, as in the lamb episode with Miss Lonelyhearts and his college friends (9-10), or the "arm 
twisting" incident with the Clean old Man (18). To make the world speak, we must, for West, make its violence audible: to spell out what the world is unaware of, to reveal ever new layers of chaos.

\section{Performative Violence}

12 West's vernacular of violence cannot be separated from the performative and dramatic images of violence. And yet this vernacular is formed from what Wolfgang Iser has called the relation of text to context and, more specifically, the "rearrangement of [social, cultural, historical, and literary] systems" when selected features from such systems resurface in the text:

The selection disassembles their given order, thereby turning them into objects for observation. The literary text, therefore, does not copy the referential field to which it relates; instead it is a reaction to the extratextual systems whose elements have been incorporated into the text. (312)

13 West responds in his own performative vernacular to the questions rising out of the systems of the text's environment. In this way, he pushes the modern intellect, as he pushes any kind of understanding of violence, into cognitive dissonance, polyvalent definitions, contingency, and equivocal allocation.

A new product is created, one which is purposefully at a remove from the "real"-and in the domain of sheer performance. As part of West's performative design, Miss Lonelyhearts is usually a "silent audito[r] for the extended and formal speech of others" (Reid 53). And yet he does try to control his own performance, adopting, for example, a theatrical image to express the fantasy of regeneration: "[H]e found himself on the stage of a crowded theater. He was a magician who did tricks with doorknobs. At his command, they bled, flowered, spoke" (9). His success in doing so, however, becomes more tenuous and problematic as the novel progresses. When, for example, he gets angry at Betty, his stage mannerisms subvert his anger: "He began to shout at her, accompanying his shouts with gestures that were too appropriate, like those of an oldfashioned actor" (12). Moments later he underscores the artificiality of his own words: "What's the matter, sweetheart. Didn't you like the performance" (13). Similarly, Miss Lonelyhearts's heightened theatricalism destroys his attempt to preach love to the Doyles: "He tried again by becoming hysterical. 'Christ is love', he screamed at them. It was a stage scream, but he kept on"(49). Each scene in the novel depicts Miss Lonelyhearts as masquerading, role-playing, performing for himself and others. Each scene works towards West's objective to create a textual world not to be viewed as a reality, but as if it were a reality.

15 The performative and the enforced pretending of a role apply, of course, to Lonelyhearts's alter ego, Shrike, and the other characters. Shrike, a self-conscious actor, deliberately exploits the artificiality of his role, as in the chapter, "Miss Lonelyhearts Attends a Party," when he addresses the tortured Miss Lonelyhearts:

"You are plunging into a world of misery and suffering, peopled by creatures who are strangers to everything but disease and policemen. Harried by one, they are hurried by the other."... "Pain, pain, pain, the dull, sordid, gnawing, chronic pain of heart and brain. The pain that only a great spiritual liniment can relieve." (53)

Shrike fabricates his speeches in advance, collecting and delivering quasi-parables, classical and Biblical quotations, topical epigrams while staging, in effect, what he wishes 
to understand or, inversely, what is unknowable to him. Miss Lonelyhearts largely substitutes the conventions of stage speech-soliloquy and monologue-for ordinary conversation, but makes this stage speech plausible by using such self-dramatizing characters as Miss Lonelyhearts, Mary Shrike, William Shrike, and Fay Doyle. The performative in Miss Lonelyhearts underscores the idea that we can only get at inaccessible realities by staging what is withheld and by making clear that whatever is repeated in the text is not meant to denote the actual world, but merely a world enacted.

Miss Lonelyhearts's violent tropes not only appear in forms of dialogue but also in performative figures of speech. To note a few examples: when Lonelyhearts's callous colleague Goldsmith smiled, he was "bunching his fat cheeks like twin rolls of smooth toilet paper" (5). When the handicapped Doyle hobbled across the barroom, "he made many waste motions, like that of a partially destroyed insect" (44). When Shrike chides how Miss Lonelyhearts might have come to his beliefs, Miss Lonelyhearts "smiled at Shrike as the saints are supposed to have smiled at those about to martyr them" (44). The tropes resonate with mechanical artifice and hysterical masquerade. West's strategy in using such language privileges the performative aspect of the author-text-reader relationship, whereby the pregiven-1930s Depression America-is no longer viewed as, in Iser's words, "an object of representation but rather as material from which something new is fashioned" ("Play", 325). Miss Lonelyhearts attempts to present through feigned representations what can never become present to ourselves, what eludes cognition and knowledge, what is beyond our experience.

\section{Dream-like Violence}

One of the signal achievements of Miss Lonelyhearts, is that West takes the modernist cliché of the artist as hero, where the artist becomes "the higher example of and the only escape from the common predicament" (Blackmur 43), and returns him to the center of experiences, including those of violence. Miss Lonelyhearts is the principal protagonistwitness to threats and acts of violence: when, for example, "Shrike raise[s] his fist as though to strike [Miss Farkis]" (7); or when Miss Lonelyhearts, in the Doyle apartment, sees "Mrs. Doyle rol[1] a newspaper into a club and str[ike] her husband on the mouth with it" (48); or when he later witnesses Mr. Doyle "pull[ing] his hand away as though to strike his wife" (49). At the experiential center of these scenes, Miss Lonelyhearts cannot fail but to participate; he is the violent victim or instrument, uninterpretable to himself, uncontrollable to others.

But such literal acts of violence are much rarer than West's imagined and dream-like violence, which is usually accompanied by the absence of a constitutive or accumulative self-consciousness, the absence of a critically sustained self-reflexive structure in the protagonist. Rather, paralleling West's performative violence, dreamlike violence usually takes the form, for Miss Lonely- hearts, of a momentary stimulus and response, of an intermittent consciousness, a temporary fighting of "misery with dreams" (39). When Miss Lonelyhearts, for example, returns to the Bronx slums after his sojourn with Betty in the country, he observes:

Crowds of people moved through the street with a dream-like violence. As he looked at their broken hands and torn mouths he was overwhelmed by the desire to help them, and because this desire was sincere, he was happy despite the feeling of guilt which accompanied it. (39) 

Flannery O'Connor's words, "feel" the text because the author has "operated" through the reader's senses; it also serves as a counter to Miss Lonelyhearts's ineffectual visionary language, which is drained of content and conviction, so that it removes him from his audience's desires. The problem is that the sources of his spiritual inspiration seem too literary for the audience they are designed to convert. Miss Lonelyhearts's God, the God of Rimbaud and Dostoevsky, is far too recondite to meet the claims of the "sick of it all" and the "desperate" who write to him at the Post-Dispatch. But this is of little concern to Miss Lonelyhearts, for his dream life obviates public involvement and acknowledgement while creating yet more discomfort and more danger-and new, less calculable, less curable risks.

\section{Effects of Violence: Reader Directed}

Miss Lonelyhearts elevates West's vernacular to the central action, and creates a violent action of language directed both against the reader and against the characters. In the case of the characters, violence is the precursor of some kind of revelation, though this may be experienced as terror, inexpressible suffering, or death itself. Miss Lonelyhearts's violent sacrifice of the lamb in Chapter 3, for example, prefigures his own violent death at the hands of Doyle. In the case of the reader, West almost appears to take delight in turning on his audiences a mocking vindictiveness. On this count, though, West's primary voice is Shrike whose verbal cruelty towards Miss Lonelyhearts, an analogue to the Post-Dispatch readers (and in certain ways to the readers of Miss Lonelyhearts), destroys all idealizations and forms of spiritualization; his is a verbal cruelty that signals and defines the relationships in the novel. Thus power and identity in Miss Lonelyhearts depend on the possession of the most potently violent verbal style-and Shrike has it.

It is specifically through this style that language takes the form of aggression and illuminates new connections between dramatic language and dramatic violence. Witness this passage in which Shrike expresses his "gospel" to Miss Lonelyhearts:

And then, the man, the man Miss Lonelyhearts-straggling valiantly to realize a high ideal, his course shaped by a proud aim. But, alas, cold and scornful, the world heaps obstacle after obstacle in his path; deems he the goal at hand, a voice of thunder bids him "Halt!"

"Let each hindrance be thy leader," thinks he. "Higher, even higher, mount!" And so he climbs, rang by weary rang, and so he urges himself, on, breathless with hallowed fire. And so... (54)

Shrike employs here his typical deflationary technique, which includes the reader as his target. Just as the main characters are subjected to violent and unanticipated denouements, the force of which depends on an ironic incongruity between situation and outcome, so the reader experiences the same shock of unpreparedness (which can lead to reader revelation) as his or her anticipations are overturned. The reader is constantly 
surprised, and kept off balance, by the violence in the text, a violence that in West is the alter-ego of language, its permanent companion-indeed its normal condition.

A primary target, then, of West's violent vernacular is the reader, who is relatively privy to Miss Lonelyhearts's inner life ("we have no outer life, only an inner one, and that by necessity" [15]). An understanding of the violence in Miss Lonelyhearts, West suggests, is a prerequisite for understanding this inner life; indeed, it is inseparable from it. For West, knowledge is not possible as a simple reproduction of its object, for he does not conceive the faithfulness of reproduction as the criterion for knowledge itself. Thus in Miss Lonelyhearts he makes clear that "every form of knowledge represents a translation of immediately given data into a new language, a language with its own intrinsic forms, categories, and requirements" (Simmel 77). From this language is bom a "new" violence, put into a modernist vernacular, which becomes the only possible response to Miss Lonelyhearts's frustration, desperateness, and his perceived conduit to survival.

\section{Sexual Suffering and Violence}

Consequently, there is a seemingly instinctive preoccupation with violence, and specifically sexual violence, the type Miss Lonelyhearts most intimately associates with life. The letters to Miss Lonelyhearts are permeated with sexual suffering, from the nightmarish epistle of Broad Shoulders to the pathos of the Sick-of-it-all, who writes that she is expecting her eighth child in twelve years (2). This type of violence, for all the major characters, is the most impulsive, the most humiliating, the least controllable. It is a violence that, for Miss Lonelyhearts, must be grappled with individually and resolved, if at all, with private means. Sexual violence, however, is conveyed most powerfully in metaphoric redescriptions and at times in surreal "shakings" and displacements. Shrike's caressing of Miss Farkis in Delehanty's (to give an example) is described thus: "When he had reached the end, he buried his triangular face like the blade of a hatchet in her neck" (8). Or again involving Shrike, this time envisioned through his descriptions of his wife, Mary:

"She's selfish. She's a damned selfish bitch. She was a virgin when I married her and has been fighting ever since to remain one. Sleeping with her is like sleeping with a knife in one's groin". (21)

In Shrike's case, as in Miss Lonelyhearts's, metaphorical descriptions of sexuality and sexual violence often follow an actual physical encounter, as in this scene in Mrs. Doyle's apartment involving Miss Lonelyhearts and Mrs. Doyle:

After doing a few obscene steps in front of him, she sat down in his lap. He tried to fend her off, but she kept pressing her open mouth against his and when he turned away, she nuzzled his cheek. He felt like an empty bottle that is being slowly filled with warm, dirty water. (50)

The scene ends with these abrupt notes of physical violence: "She tried to pull him down on top of her. He struck out blindly and hit her in the face. She screamed and he hit her again and again" (50). Miss Lonelyhearts's impulse toward the "Divine Love of man" and "all God's creation" ultimately manifests itself in sexual cruelty (he viciously tugs at the nipples of his fiancée's breasts), self-loathing seduction (he calculatingly attempts to seduce Mary Shrike), and latent homosexuality (he brutally twists the arm of an old homosexual), all of which add up to a privatization of violence that conduces to Miss 
Lonelyhearts becoming a stranger everywhere and, his efforts to the contrary notwithstanding, at all places.

\section{Violence and the Unredeemed}

Miss Lonelyhearts eventually takes on, at least in his mind, the role of the lamb, the sacrificial Christ figure, a role hinted at by Shrike in his parody of the Anima Christi at the beginning of the novel (1). Christ imagery continues in the form of the shadow of a lamp post which pierces Miss Lonelyhearts "like a spear" (4); Miss Lonelyhearts, after offering the lamb in sacrifice in Chapter 3, becomes in turn Doyle's sacrificial victim, at the end of the text. Miss Lonelyhearts's arms are spread, in Christ-like supplication, ready for martyrdom (54). Miss Lonelyhearts is a character for whom Christ is at once a sexual and a spiritual power-and yet who is himself, by virtue of his cynical culture, too "rational" to believe in him and too exhausted and fearful to accept irrationally that source of energy.

Miss Lonelyhearts's violence finally spills over into a ritualistic language and a resultant kind of verbal hypnotism, as if, by the end of the novel, he has fully committed himself to enacting Shrike's apocalyptic pronouncements-almost all of which are troped in violence. The use of extended clichés and jargon as forms of coercion, passed on from Shrike to Miss Lonelyhearts, eventually produces a "mentally unmotivated violence" (56). In the closing pages of the novel Miss Lonelyhearts embodies a cliché that turns on him: "God had sent him so that Miss Lonelyhearts could perform a miracle and be certain of his conversion" (57). Unknown to Miss Lonelyhearts, a language speaks through him ("Christ is life and light"; "Christ! Christ!"; "I accept, I accept" [57]) that offers no recourse to intent or control. In this final scene, the victims of this language are not only those against whom it is directed (the Doyles), but also those through whom it is uttered (Miss Lonelyhearts). Miss Lonelyhearts and Doyle fall down the stairs, Miss Lonelyhearts fatally wounded, an iconic image which comes to denote the final abyss of West's vernacular, an image that reinforces the fact that, in West, violence becomes the creative energy of performance.

\section{Conclusion}

31 Leslie Fielder has argued that violence in Miss Lonelyhearts is "a technique as well as subject matter" (Fielder 49). But violence in the novel goes far beyond technique and content. It implies a wider notion of a modernist aesthetic, one that situates artistic practices within a larger history and economy of sensory perception that forms the battleground for the meaning and fate of modernity itself. While the spread of urbanindustrial technology, the large-scale disembedding of social (and gender) relations, and the shift to mass consumption (the subjects of several of the subtexts in Miss Lonelyhearts) entailed processes of real destruction and loss, there also emerged new modes of organizing vision and sensory perception, a new relationship with "things". ${ }^{3}$ Violence takes the forms of experience and expression, of affectivity, temporality, and reflexitivity, a changing fabric of everyday life. From this perspective, West's aesthetic of violence encompasses a modernist vernacular which combines the dimension of the quotidian, of everyday usage, with connotations of discourse, and with promiscuity and 
translatability. Furthermore, this aesthetic signals a juncture of the performative and modernism, reminding us that the performative was not only part and symptom of modernity's experience and perception of crisis and upheaval; it was also, for West, the single most inclusive cultural horizon in which the traumatic effects of modernity were reflected, rejected or disavowed, transmuted or negotiated.

In defining his violence as an aesthetic, West did not just circulate images and rest satisfied with symbolic, surreal, or hyper-realistic renderings; he constituted or tried to constitute in Miss Lonelyhearts new subjectivities and subjects. What he brought into consciousness on a narrative-cognitive level was how, when a text performs, it can open up hitherto unperceived modes of sensory perception and experience and suggest a different organization of the daily world. Whether this new aesthetic took the shape of dreams or nightmares, it marked a new direction in American literature of imagined violence as metaphor for a sensory idiom and vernacular. In the process, it made it possible to imagine the modernist fascination with the "low," sensational, attractionist genres, catering to a mass production of the senses, and the classical modernist ideal of formal and narrative efficiency as two vectors of the same phenomenon.

\section{BIBLIOGRAPHY}

Bolton, B. “Placing Violence, Embodying Grace: O'Connor's ‘Displaced' Person.” Studies in Short Fiction, Vol. 34, No. 1., Winter 1997: 87-104.

Blackmur, R.P. The Lion and the Honeycomb. London: Methuen, 1956.

Fielder, Leslie. Waiting for the End. New York: Stein and Day, 1964.

Iser, Wolfgang. “Do I Write for an Audience?". Publication of the Modern Language Association, Vol. 115, No. 3, May 2000: 310- 315.

Iser, Wolfgang. "The Play of the Text.", Languages of the Unsayable, Eds. Sanford Budick and Wolfgang Iser. New York: Columbia UP, 1989: 325-339.

Kowalewski, M. Deadly Musings. Princeton: Princeton UP, 1993.

Poe, Edgar Allan. The Narrative of Arthur Gordon Pym of Nantucket. New York: Penguin, 1999.

Poe, Edgar Allan. “The Poetic Principle”. Criticism: The Major Statements ( $2^{\text {nd }}$ Edition), Ed. Charles Kaplan. New York: St. Martin's Press, 1986, 336-356.

Rainey, L. and R. von Hallberg, “Editorial/Introduction”. Modernism/Modernity, Vol. 1, No. 1, January 1994: 1-3.

Reid, R. The Fiction of Nathanael West. Chicago, U of Chicago P, 1967.

Simmel, G. The Problems of the Philosophy of History, Trans. Guy Oakes. New York: Free Press, 1977.

West, Nathanael. Miss Lonelyhearts and The Day of the Locust. New York: New Directions, 1962.

West, Nathanael. “Some Notes on Miss Lonelyhearts”. Contempo, May 15, 1933: 2.

West, Nathanael. “Some Notes on Violence". Contact, October 1932: 132. 


\section{NOTES}

1. See Richard Slotkin, Regeneration through Violence, Middleton, Wesleyan University Press, 1973.

2. This study assumes a notion of modernism that is "more than a repertory of artistic styles," more than sets of ideas pursued by groups of artists and intellectuals (Rainey 1). Rather, modernism encompasses a whole range of cultural and artistic practices that register, respond to, and reflect upon processes of modernization and the experience of modernity, including a paradigmatic transformation of the conditions under which art is produced, transmitted, and consumed. In other words, just as modernist aesthetics are not reducible to the category of style, they tend to blur the boundaries of the institution of art in its traditional, eighteenth- and nineteenth-century incarnation that turns on the ideal of aesthetic autonomy and the distinction of "high" vs. "low," of autonomous art vs. popular and mass culture.

3. Such an idea is suggested by West in the chapter "Miss Lonelyhearts and the Cripple". In a culture of materiality, everything, even words, become materialized: "[Doyle] was giving birth to groups of words that lived inside him as things, a jumble of the retorts he had meant to make when insulted and the private curses against fate that experience had taught him to swallow" (45-46).

\section{INDEX}

oeuvrecitee Miss Lonelyhearts 